\title{
Konstansie en verandering in God se verlossingsplan
}

NGTT DEEL 55, NO 1, 2014

\section{Snyman, AH}

Universiteit van die Vrystaat

\begin{abstract}
Constancy and change in God's plan of salvation

Our everyday experience is well acquainted with the reality of constancy and change. Persistence over time (continuity) is normally accompanied by an awareness of change (discontinuity). This article wants to highlight the underlying ontological issues and distinctions required to gain a better understanding of the familiar term identity. In order to achieve this goal the idea of identity is related to the nature of an entity and its properties. Plato's account of identity and change paved the way for an enduring philosophical wrestling with this problem. In the Dooyeweerd tradition, acknowledging the more-than-functional and multi-functional nature of the identity of an entity helps us to understand the distinction between conceptual knowledge and concept-transcending knowledge.
\end{abstract}

In the first part of the article the problem of constancy and change is epistemologically investigated and described. The second part deals with the identity or theme of God's plan of salvation in both the Old and New Testament. It is argued that this theme entails an implicit awareness of the foundational relationship between constancy and change - especially in Romans 9-11, where it is used as hermeneutical strategy to explain Israel's role in salvation history, thereby providing a complementary perspective on the exegesis of this important theme in Paul's letter. Thus the article is by definition multidisciplinary. It also includes a few remarks on rhetoric and Bible translation. 


\section{INLEIDING}

Die vraag na identiteit het die Westerse denkgemeenskap deur die eeue heen besig gehou. Daar is vandag nie een wetenskaplike konteks waarin die vraag na identiteit nie sinvol gestel kan word nie. Wanneer eksegete byvoorbeeld wil stilstaan by hierdie onvermydelike gegewe van ons ervaring van die werklikheid, ontmoet ons daarin slegs 'n besondere gestalte van die aard van identiteit - of dit nou gaan oor die identiteit van 'n Nuwe Testamentiese geskrif, of oor die identiteit van 'n bepaalde teologiese tema, of selfs oor die identiteit van 'n skrywer.

Die vraag na identiteit duik nooit in isolasie op nie; dit word gewoonlik minstens gekoppel aan die ewe-grondliggende probleem van verandering. Van die vroegste tye is die vraag immers gestel of daar te midde van 'n voortdurend-veranderende werklikheid hoegenaamd enige plek kan wees vir die besef van identiteit. Selfs wanneer daar pogings aangewend is om tot 'n positiewe waardering van identiteit en verandering te kom, wil dit lyk asof die een slegs sinvol verantwoord kan word indien tegelyk ook rekening gehou word met, en rekenskap gegee word van, die ander een. Identiteit en verandering skyn onverbreeklik met mekaar saam te hang.

In die artikel word die problematiek van identiteit en verandering allereers aan 'n breër epistemologiese ondersoek onderwerp. Daarna word die identiteit of tema van God se verlossingsplan aan die hand daarvan beskryf. In die proses word aangetoon dat die identiteit van dié belangrike tema in die teologie ten nouste saamhang met die fundamentele verhouding tussen konstansie en verandering - veral in Romeine 9-11, waar Paulus dit as hermeneutiese strategie gebruik om Israel se rol in God se verlossingsplan te verduidelik. Deur dié filosofiese benadering word 'n aanvullende perspektief op die eksegese van die brief gebied, terwyl enkele opmerkings oor retoriese middele en Bybelvertaling ook deel vorm van dié multidissiplinêre studie.

\section{KENTEORETIESE RAAMWERK I.S. IDENTITEIT}

Studente wat in die jare dertig van die vorige eeu by prof. N. Diedericks filosofie gestudeer het, vertel dat hy altyd die voorbeeld van 'n trapfiets gebruik het om twee sake duidelik te maak:

- die geheel is meer as die som van die dele en

- die wisseling van die dele hef nie die identiteit van die fiets op nie.

Die binnebande, buitebande, wiele, raamwerk, stuurgedeelte - en noem maar op - kan almal opeenvolgend verwissel word en nog steeds word van dieselfde fiets gepraat. Die fiets besit klaarblyklik die vermoë om te midde van die wisseling van 
bepaalde onderdele 'n intrinsieke duursaamheid te vertoon - te midde van (en ongeag) alle veranderinge bly dit "dieselfde" fiets.

In sy dialoog Kratylos (402A) worstel Plato reeds met die probleem van konstansie en verandering, en wel na aanleiding van Herakleitos se opmerking dat ons nie twee keer in dieselfde rivier kan instap nie, aangesien die watermassa voortdurend wissel. Later sou Plutarchos dieselfde probleem illustreer aan die hand van die skip van Thesius: in die loop van jare het die Ateners uiteindelik elke plank waaruit die skip opgebou is, vervang; wat die vraag laat ontstaan of ons nog sinvol van dieselfde skip kan praat.

Plato was veral besorg oor die implikasies wat die stelling dat alles voortdurend verander, inhou, want wanneer iemand sou beweer dat iets in kennis vervat is, het dit die volgende oomblik reeds in iets anders verander - wat die moontlikheid van kennis prinsipieel ophef. Gevolglik postuleer hy, ter wille van die kenbaarheid van dinge, die staties-onveranderlike "eie wese" ("auto to eidos") van dinge, dit is, hulle bo-sinnelike en ewig-onveranderlike wese, hulle ideë. Laasgenoemde is slegs verstandelik te bedink, terwyl die sigbare (veranderlike) met die sinne waargeneem kan word. Hierdie onderskeiding hang natuurlik saam met die dualistiese inslag van die Griekse grondmotief van vorm en materie, waarvolgens die werklikheid by Plato verdeel is in die ryk van die sigbare dinge (bestempel as die ryk van wording: genesis) en die ryk van die selfstandig-bestaande dinge (ousiai) (Strauss 1978:122).

Die belangrike gesigspunt in Herakleitos se probleemstelling is gegee in die klaarblyklike gesamentlike teenwoordigheid van verandering én duursaamheid. Die unieke en onverganklike bydrae van Plato is gegee in sy insig dat verandering alleen vasgestel kan word op basis van konstansie (duursaamheid) (Strauss 2004:564-5). Hierdie insig strook met ons alledaagse lewenservaring, want wanneer ons na 'n foto van iemand kyk wat 20 of 30 jaar gelede geneem is, kan ons maklik sien dat daar veranderinge ingetree het. Op grond waarvan kan hierdie veranderinge egter vasgestel word? Die antwoord is veelseggend: op grond van die feit dat ons steeds van dieselfde persoon praat!

Plato het dus ingesien dat verandering slegs op die basis van konstansie (soos gegee in sy ryk van ideë) vasgestel kan word. Later sou Aristoteles hierop reageer deur Plato se ideë "af te trek" na dit wat hy bestempel het as die universele wesensvorme van dinge. In sy Metaph (1039b, 22-26) stel hy byvoorbeeld dat wanneer hierdie huis vergaan, dit nie huis-wees is wat vergaan nie: in die huis-wéés van elke huis tóón daardie huis op 'n universele manier dat dit gekoppel is aan dit wat geld vir huiswees in die algemeen. Waar Plato dus die orde vir die werklikheid ontdek het - 'n orde wat as die wet-vir-skepsel-wees die konstante kader vorm waarbinne konkrete 
dinge hulle variabele bestaansruimte vind, daar het Aristoteles die ordelikheid van die dinge raakgesien - wat as korrelaat van die orde vir die dinge dien (Strauss 2009:176-177).

Laasgenoemde opmerkings bring ons binne die kader van die christelikreformatoriese wysbegeerte as nog 'n voorbeeld van hoe wysgere met die onderskeiding tussen konstansie en verandering werk in 'n poging om ons kenniservaring van'n gegewe in die werklikheid te verklaar. Christelik-wysgerig beskou kan die duursame voortbestaan van enige gegewe, waarin dit behoue bly te midde van al die veranderinge wat dit ondergaan, slegs benader word deur die toegangspoort van die modaliteite. Voortbouend op Dooyeweerd (1997, Vol. III:65) se teorie van die modale aspekte van die werklikheid (soos getal, ruimte, beweging, die fisiese, die logiese, ens.) verduidelik Strauss (2009:179) ons ervaring van identiteit aan die hand van die veelsydigheid (menigvuldige aspekte) waarin ons dinge en gebeurtenisse in hulle duursaamheid beleef. Sy konklusie is dat ons moet onderskei tussen die gebruik van aspek-terme as ons verwys na iets wat binne die grense van die betrokke aspek funksioneer en die gebruik van aspek-terme waarin hulle benut word op 'n wyse wat ons tot buite die grense van die betrokke aspek heenvoer. Die eerste soort gebruik van aspek-terme noem hy'n begrips-gebruik daarvan, die tweede 'n begripstransenderende gebruik daarvan. Begripsvorming berus normaalweg op 'n veelheid universele kenmerke, wat saamgebind word in die eenheid van 'n begrip. Ons besef van die identiteit van dinge en gebeurtenisse berus nou enersyds op hierdie veelheid van universele kenmerke wat die grense van begrips-vorming oorskry, en andersyds berus dit op die rol wat die funderende samehang tussen die kinematiese (bewegings) en fisiese aspekte van die werklikheid in ons identiteitservaring speel.

Hoewel vanuit radikaal-verskillende gesigshoeke, kom bogenoemde denkrigtings ooreen dáárin dat die identiteit van 'n geskrif of teologiese tema bepaal word deur die nosies van kontinuïteit (duursaamheid, konstansie) én diskontinuïteit (verandering). Ons besinning oor 'n tema wat konstant of duursaam aanwesig is, kan dus veranderende of variërende interpretasies hê. Danksy die onderliggende konstansie kan ons egter die veranderinge vasstel. Wanneer dergelike veranderinge nie die konstansie van 'n gegewe ophef nie, ontmoet ons 'n verantwoorde besef van die identiteit daarvan. Dan ken ons dit.

\section{GOD SE VERLOSSINGSPLAN WYSGERIG BESKOU}

Ten einde God se verlossingsplan te verstaan, word vervolgens aandag gegee aan konstansie én verandering. 


\subsection{Konstansie}

Daar is konstansie t.o.v.

- God se plan met die nasies, en

- diegene wat die objek van verlossing is.

Eerstens: konstansie in God se verlossingsplan. Die Here wou hê dat Israel naby Hom moes leef - nie net ter wille van hulleself nie, maar ook ter wille van al die ander nasies. As God van die hele wêreld, wou Hy deur Israel al die heidennasies bereik (König 2001:20-21). Dit was deel van sy oorspronklike plan toe Hy die verbond met Abraham gesluit het: "En Ek sal jou 'n groot nasie maak en jou seën en jou naam so groot maak dat jy'n seën sal wees. En Ek sal seën diegene wat jou seën en hom vervloek wat jou vervloek; en in jou sal al die geslagte van die aarde geseën word" (Gen. 12:2-3). Dié seën hou dus eerstens in dat Abraham en sy nageslag 'n groot volk sal word, 'n nuwe en afsonderlike volk, wat sy bestaan tot by hom sal terugvoer. Tweedens spreek die belofte daarvan dat Abraham ook vir ander volkere tot 'n seën sal wees, dat in hóm al die ander nasies op aarde geseën sal word (Aalders 1963:17-18). Veral laasgenoemde is vir ons doel belangrik: die seën is nie beperk tot Abraham en sy nageslag nie, maar dit is bedoel vir al die nasies.

Dat God deur Abraham en sy nageslag (Israel) die heidennasies wou bereik, blyk ook uit Miga 4:1-4, wat feitlik woordeliks aangehaal word in Jes. 2:2-4: "Daar kom 'n tyd dat die berg waarop die huis van die Here is, 'n blywende plek sal hê bokant die bergtoppe en sal uitstaan bo die heuwels. Die volke sal daarheen stroom, baie nasies sal daarnatoe gaan en sê: 'Kom, laat ons optrek na die berg van die Here toe, na die huis van die God van Jakob, sodat Hy ons sy wil kan leer en ons daarvolgens kan lewe, want uit Sion kom die openbaring, uit Jerusalem die woord van die Here". Volgens König (2001:20-21) was dít God se verlossingsplan: As Israel in sy weë sou wandel, sou Hy hulle só voorspoedig maak dat al die volke na Jerusalem sou stroom en sou erken dat hiérdie volk die enigste ware God aanbid, volgens Wie se wil hulle begeer om te lewe. Só wou God die wêreld verlos: deur Israel te seën en op dié wyse die heidennasies jaloers te maak en nader te trek na Hom toe. 'n Wesenlike deel van dié seën was dat alle oorloë sou ophou (Miga 4:3-4) en die Here Israel van al sy vyande sou bevry.

Ongelukkig was Israel ontrou aan die Here en het die nasies nie na Jerusalem toe gestroom nie. Het dit meegebring dat God van sy verlossingsplan afgesien het? Nee. Die gevolg van Israel se ontrou was dat Hy vir Jesus as 'n tipiese Ou-Testamentiese profeet gestuur het om hulle tot bekering te roep, sodat Hy steeds sy plan deur Israel met die heidene kon uitvoer. Die feit dat God vir Jesus juis na Israel toe gestuur het en só die heidene wou bereik, bevestig die konstansie in God se verlossingsplan. Met 
verskeie bewyse uit Matteus, Lukas en Handelinge beredeneer König (2001:22-24) hierdie punt op oortuigende wyse. Reeds by Jesus se geboorte sê die engel vir Josef: "Sy sal 'n Seun in die wêreld bring, en jy moet Hom Jesus noem, want dit is Hy wat sy volk van hulle sondes sal verlos" (Matt. 1:21). "Sy volk" verwys na die volk Israel. Later gee Jesus self die volgende opdrag aan sy twaalf dissipels: "Moenie met 'n pad na die heidennasies toe afdraai nie en moenie in 'n dorp van die Samaritane ingaan nie. Gaan liewer na die verlore skape van die volk Israel toe. Gaan verkondig: 'Die koninkryk van die hemel het naby gekom' “ (Matt. 10:5-7). En toe die dissipels Hom vra waarom Hy nie reageer op die smeking van die Kanaänitiese vrou nie, antwoord Hy reguit: "Ek is net na die verlore skape van die volk Israel toe gestuur" (Matt. $15: 24)$.

Dieselfde toespitsing op Israel vind ons in die lofsange op die geboortes van Jesus en Johannes die doper, soos Lukas dit beskrywe in hoofstuk 1:46-55 (die loflied van Maria) en 1:68-79 (die lofsang van Sagaria). Uit Handelinge 3:26 en 5:31 is dit duidelik dat Petrus dit ook so verstaan het dat Jesus se bediening aanvanklik net op Israel gerig was. Selfs ná die uitstorting van die Heilige Gees het Petrus nog steeds 'n probleem gehad om in die huis van 'n heiden in te gaan (Hand. 10). Veel later het ook Paulus in elke stad allereers na die sinagoge toe gegaan om die Jode te probeer oortuig dat Jesus die Messias is voordat hy hom tot ander mense en take gewend het.

Daar is dus duidelik konstansie tussen die Ou en Nuwe Testament (by name die Evangelies en Handelinge) t.o.v. God se verlossingsplan. Tydens sy aardse optrede was Jesus getrou aan die opdrag wat die Ou-Testamentiese profete ontvang het: sy werk was allereers op Israel gerig, nie op die heidennasies nie. En so het die apostels ook hulle taak verstaan. Want: deur Israel te seën wou God die heidennasies jaloers maak en hulle nader trek na Hom toe.

Tweedens is daar konstansie t.o.v. diegene wat die objek van God se verlossing is. Van die begin af het die ware Israel nie uit al die nasate van Abraham bestaan nie, maar slegs uit die gelowiges in Israel. Die Israeliete in die ou bedeling, wat nie in God geglo het nie, was nooit deel van sy verloste volk nie; daarom was dit die taak van die profete om die ongehoorsame Israeliete telkens te waarsku dat God hulle sal verwerp as hulle hulle nie bekeer nie, dat Hy hulle as heidene ("Kussiete" in Amos 9:7) sal beskou. In Rom. 9:6-8 verwoord Paulus hierdie belangrike onderskeiding soos volg: "Immers, nie almal wat van Israel afstam, is werklik (= die ware) Israel nie; en nie almal wat nakomelinge van Abraham is, is werklik kinders van Abraham nie ... Dit is nie die kinders wat in die gewone gang van die lewe (= op natuurlike wyse) gebore is, wat kinders van God is nie; dit is die kinders wat kragtens die belofte (= op bo-natuurlike wyse) gebore is, wat as Abraham se nageslag gereken word". In die 1983-vertaling hier aangehaal, is daar slegs by implikasie 'n kontras 
tussen die twee soorte kinders. Die Grieks merk die kontras egter uitdruklik met die teenstellende à $\lambda \lambda \alpha$ ( "maar"), wat tereg in die Nuwe Testament en Psalms. 'n Direkte Vertaling (2014) so vertaal is. En die frase "die belofte van God", beskryf Lenski (1961:594) as "the covenant promise, the gospel or Christ promise, which brings forth children of God by faith and by faith alone". Slegs hulle wat op dié wyse gebore is, is die ware Israel.

Met 'n reeks aanhalings uit die Ou Testament (Gen. 21:12; 18:10,14; 25:23; Mal.1:23; Eks. 33:19 en 9:16) bring Paulus nou bogenoemde waarheid oor kinders, wat volgens die belofte van God gebore is, tuis in die res van sy argument (9:7b-18). Hieruit blyk dat God se uitverkiesing en barmhartigheid bepaal wie sy kinders is, en nie natuurlike afstamming of menslike handelinge nie. Tolmie (2005: 96, 109-124, 194-195) beskryf sulke aanhalings as argumente gebaseer op die gesag van die Skrif. Hulle is retories effektief, omdat hulle deur die gehoor as gesaghebbend aanvaar word. Die aanhalings versterk die band tussen Paulus en sy gehoor, hulle bind albei partye aan die God van Israel en word deur Paulus in goed-gestruktureerde beredenerings ingebed - dikwels nadat hy hulle ietwat aangepas het om die verband tussen die sitaat en sy argumentasie duidelik te maak (Stanley 1998:712-716).

Kinders wat volgens die belofte gebore is, sluit die heidene wat tot geloof in die God van Abraham kom, in. Hulle is deel van die ware Israel. Dit was juis die doel van God se verbond met Abraham in Gen. 12:3: dat in hom al die geslagte van die aarde geseën sal word.

In God se verlossingsplan is daar dus duidelik konstansie t.o.v. wie verlos word. Hulle is die ware Israel, die uitverkorenes uit die Jode en die heidene - almal van wie Abraham die vader is. Wat die Jode betref, is dit die oorblyfsel wat God in sy genade uitverkies het. In die oorspronklike Grieks van 11:5 is die woord "genade" in die genitief en verbind aan "verkiesing", wat in effek neerkom op vrye toegang tot God en bepaalde voordele, wat onverdienstelike mense slegs deur Christus se soenverdienste ontvang (Harrison 2003:224-225). Die kern van die saak is dat God net één volk het: die ware Israel, wat uit al die nasies versamel word op basis van geloof alleen - en dit van die begin af tot by die wederkoms van Christus (König 2001:30-31).

\subsection{Verandering}

Naas konstansie is daar ook verandering in God se verlossingsplan. Die verandering word duidelik uitgespel in Rom. 9-11. In sy gevolgtrekking oor die uitverkiesing skryf Paulus in 9:30-33: "Heidene het nie God se vryspraak gesoek nie, maar dit wel gekry - die vryspraak deur die geloof. Israel, daarenteen, het'n wet gesoek waardeur 
hulle God se vryspraak sou kon kry, maar by so 'n wet het hulle nie uitgekom nie. Waarom kon hulle die vryspraak nie kry nie? Omdat hulle nie op die geloof wou bou nie, maar op hulle eie prestasies. Hulle het oor die struikelblok gestruikel, soos daar geskryf staan ..." En dan volg weer 'n argument gebaseer op die gesag van die Skrif as Paulus aanhaal uit Jes. 8:14.

Bogenoemde vertaling van 9:30-33 kom uit die 1983-vertaling. Die vertaling

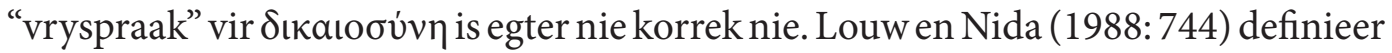

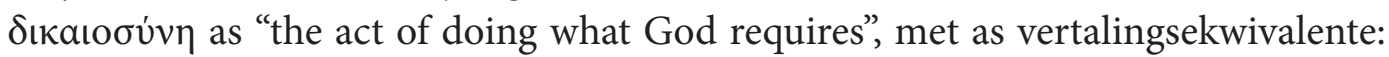
"righteousness, doing what God requires, doing what is right ". Die Nuwe Testament

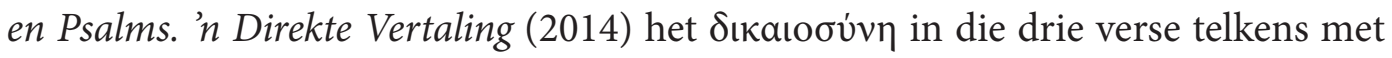
"geregtigheid" vertaal, wat die oorspronklike tot sy reg laat kom.

In hoofstuk 11 brei Paulus nou uit op die struikeling in 9:30-33 as hy in 11:11 vra: "Het Israel se struikeling hulle finale val beteken?" Sy antwoord is: "Beslis nie ( $\mu$ ทे $\gamma \dot{\varepsilon}$ voıto). Maar deur hulle val het die redding na die heidennasies toe gekom om die Jode jaloers te maak". En in 11:13-14 praat hy spesifiek met die gelowiges uit die heidennasies as hy sê dat sy taak as apostel is "om op een of ander manier ( $\varepsilon^{\prime \prime}$ $\pi \omega \varsigma)$ my eie mense (= die Jode) jaloers te maak en sommige van hulle te red" (1983 vertaling). Jewett (2007:679) wys op die versigtige wyse waarop Paulus sy taak in die oorspronklike Grieks formuleer. Die werkwoorde $\pi \alpha \rho \alpha \zeta \eta \lambda \omega \sigma \omega$ (“jaloers maak”) en $\sigma \omega \sigma \omega$ ("red") kan albei verstaan word as futurum indikatief of aoristus subjunktief, wat 'n belangrike verskil aan die vertaling daarvan maak. Jewett kies vir die aoristus subjunktief, en wel in die lig van die versigtige formulering $\varepsilon^{\prime l} \pi \omega \varsigma$, wat die werkwoorde voorafgaan, sowel as die "sommige" wat gered kan word. Sy motivering oortuig en gevolglik steun ek sy vertaling van die aoristus subjunktiewe met "might make jealous" en "might save". So verstaan, erken Paulus dat die verlossing van Israel ten diepste God se werk is en nie syne nie. Op die wyse laat hy die oorreding van die Jode, wat steeds weerstand bied teen die evangelie, in God se hande. Hy strewe slegs daarna dat sy werk op een of ander manier sy eie mense jaloers kan maak en sommige van hulle kan red.

Hierdie versigtige formulering kom tot sy reg in die Nuwe Testament en Psalms: 'n Direkte vertaling, wat lees: “ (ek heg groot waarde aan my bediening as apostel van die heidene) in die hoop dat ek dalk my eie mense jaloers kan maak en sommige van hulle tot verlossing kan bring" (11:13-14).

Waar God se verlossingsplan dus aanvanklik daarin bestaan het om die (gehoorsame) Israeliete ryklik te seën en op dié wyse die heidennasies jaloers te maak en na Hom toe te trek, daar hoop Paulus nou dat die gelowige heidene, op hulle beurt, die ongelowige Jode jaloers sal maak sodat hulle Jesus as Verlosser sal aanvaar. Kortom: 
die verlossing van die ongelowige Jode is die resultaat van hulle jaloesie op die gelowige heidene (Louw 1979:111). Volgens Paulus is dit die enigste toekoms vir die Jode: dat hulle jaloers gemaak kan word op hulle eie Messias en Hom in die geloof kan aanvaar. En in die proses het hy as apostel 'n beskeie funksie. Die oorreding van die Jode, wat soveel weerstand bied teen die evangelie, is in eintlike sin God se werk.

Bogenoemde verandering in God se verlossingsplan word in 11:16-24 verduidelik aan die hand van die beeld van 'n olyfboom: die ongelowige Jode is soos takke wat uitgekap is uit die mak olyf ( = die ware Israel), terwyl die gelowige heidene as takke van 'n wilde olyfboom op die mak olyf geënt is - slegs omdat hulle glo. Op dié wyse kry hulle deel aan die lewensap van die mak olyf (11:17). Die metafoor van die olyfboom is die kragtigste oorredingsmiddel wat in 11:11-24 gebruik word (Maartens 1997:1007-1009; Witherington 2004:240) en kan gedefinieer word as 'n skuif in verwagting m.b.t. die kommunikasieproses - gewoonlik van 'n letterlike na 'n figuurlike betekenis, soos hier in 11:16-24 (Nida, Louw, Snyman, Cronje 1983:186). Op die wyse word die gehoor voorsien van 'n nuwe, ongewone kyk op 'n saak, wat hulle aandag skerper daarop fokus (Tolmie 2005:99).

Benewens die funksie van die metafoor, is die volgende twee punte ook belangrik vanuit 'n oorredingsperspektief. Die eerste is weer die passief "is uitgekap" ( $\dot{\xi} \xi \kappa \lambda \alpha \dot{\sigma} \sigma \eta\rceil \sigma v)$, wat deur Dunn (1988:660) gedefinieer word as 'n passivum divinum. Wat taalkundiges en eksegete tereg só definieer, kan vanuit retoriese hoek beskou word as 'n argument gebaseer op goddelike betrokkenheid. Die soort argument is effektief, omdat dit God, as die hoogste gesag vir spreker en hoorder, betrek by die handeling en dus die einde van alle teenspraak beteken. Dit oorreed, omdat gelowiges God se gesag aanvaar en in sy beskikking berus. In die gang van die argument in hoofstuk 11 is dit ook belangrik dat God net "party van die takke" afgebreek en nie sy volk as geheel verwerp het nie. Tweedens skakel Paulus in 11:17 van die derde persoon meervoud in 11:11-16 oor na die tweede persoon enkelvoud, wat impliseer dat hy elke individuele heiden-christen direk wil aanspreek: jý, as 'n wilde olyf, is tussen die ander takke op die mak olyf geënt. Op die wyse word 'n christen uit die heidendom as gespreksgenoot ingevoer, wat as verpersoonlikte tak van die wilde olyfboom op die mak olyfboom van Israel ingeënt is (Tobin 2004:363). Die gesprek tussen die twee gespreksgenote ("jy" en "hulle" = die ongelowige Jode) word voortgesit tot by 11:24. Die tweede persoon enkelvoud $\sigma$ v́, wat in vers 17 ingevoer word, staan aan die begin van die betrokke sinsdeel in 'n beklemtoonde posisie en die gespreksvennoot verleen 'n lewendige effek aan die argument (Anderson 2000:237-8; Witherington 2004:179).

Die inenting van die wilde olyf "tussen / onder hulle" ('̉v aủtoĩ in 11:17) verwys binne konteks na die takke wat nie afgebreek is nie, d.w.s. na die Joodse christene. 


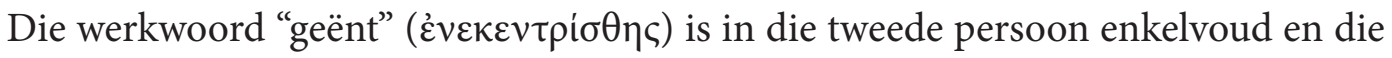
passief is weer 'n passivum divinum, wat goddelike betrokkenheid impliseer.

Ten slotte is dit duidelik dat die Jode 'n besondere plek in God se verlossingsplan inneem. In God se oorspronklike plan het Israel 'n sentrale rol gespeel: Hy wou hulle só ryklik seën dat die heidennasies na Jerusalem sou stroom om Hom daar te kom dien. Selfs Jesus, as die grootste van alle profete, se bediening was allereers toegespits op die welsyn van die Joodse volk. Toe Israel egter ontrou word, en veral toe hulle vir Christus verwerp, het God sy plan verander. Christus se kruisdood was die keerpunt. In die hersiene plan neem Israel weer 'n sentrale plek in: nou is die apostels na die heidene toe gestuur sodat hulle vir Israel jaloers kan maak op hulle eie Messias. In dié sin is die redding of verlossing van die Jode die diepste motivering vir Paulus se taak as heidenapostel.

Deur verskeie retoriese middele probeer Paulus in Rom. 9-11 sy hoorders oorreed om sy standpunt oor die posisie van Israel in God se verlossingsplan te deel. Dit is die enigste toekoms wat hy vir Israel sien.

\section{KONKLUSIE}

Die hermeneutiese strategie wat in die Skrif gebruik is om die identiteit of tema van God se verlossingsplan te ontwikkel, is dié van konstansie en verandering. In die artikel is die onderskeiding eers wysgerig begrond, waarna dit gebruik is om die verlossingsplan te beskryf. Die konklusie van dié multidissiplinêre studie is dat daar konstansie en verandering in God se verlossingsplan is en dat albei die momente verreken moet word as ons 'n greep wil kry op die tema van God se omvattende verlossingsplan vir die wêreld. Wysgerig beskou, geld die nosies van konstansie én verandering immers vir ons verstaan van enige gegewe in die werklikheid.

Enkele oorredingsmiddele is in Rom. 9-11 geïdentifiseer en hulle funksies binne konteks beskryf. Uit die studie het ook 'n paar opmerkings voortgevloei, wat Bybelvertalers mag interesseer. Dit is duidelik dat die nuwe 2014 Afrikaanse vertaling voorsien in die behoefte van ernstige Bybelstudente, omdat dit alles wat die bronteks kenmerk, so getrou moontlik weergee.

\section{BIBLIOGRAFIE}

Aalders, G Ch 1960. Het Boek Genesis. Korte Verklaring der Heilige Schrift. J.H.Kok N.V.Kampen. 
Anderson, R D 2000. Glossary of Greek Rhetorical Terms Connected to Methods of Argumentation, Figures and Tropes from Anaximenes to Quintilian. CBET 24. Leuven: Peeters.

Dooyeweerd, H 1997. A New Critique of Theoretical Thought. Collected Works of Herman Dooyeweerd, A-Series Vols. 1-1v. (General Editor D. F. M. Strauss). Lewiston: The Edwin Mellen Press.

Dunn, J D G 1988. Romans 1-8; Romans 9-16. 2 vols. WBC 38a, 38b. Dallas: Word. Jewett, R 2007. Romans. A Commentary. Minneapolis: Fortress Press.

König, A 2001. Die helfte is my nooit oor Jesus vertel nie.

Wellington: Lux Verbi. BM.

Lenski, R C H 1961. The Interpretation of St. Paul's Epistle to the Romans. Minneapolis: Augsburg Publishing House.

Louw, J P 1979. A Semantic Discourse Analysis of Romans. 2 vols. Pretoria: University of Pretoria Press.

Louw, J P, \& Nida, E A 1988. Greek-English Lexicon. 2 vols. New York: UBS.

Maartens, P J 1997. "Inference and Relevance in Paul's Allegory of the Wild Olive Tree”. HTS 3: 1007-1019.

Nida, E A, Louw, J P, Snyman, A H, \& Cronje, J v W 1983. Style and Discourse. Goodwood: N.B.P.

Stanley, C D 1998. "Biblical Quotations as Rhetorical Devices in Paul's Letter to the Galatians”. SBL 1998 Seminar Papers: 700-739. Atlanta: Scholars Press.

Strauss, D F M 1978. Inleiding tot die Kosmologie. Bloemfontein: Sacum Beperk.

Strauss, D F M 2004. “ 'Eat it again for the first time': Identity in a World of Change”. Koers 69 (4): 555-574.

Strauss, D F M 2009. Philosophy. Discipline of the Disciplines. Grand Rapids: Paideia Press.

Tobin, T H 2004. Paul's Rhetoric in Its Context: The Argument of Romans. Peabody: Hendrickson. 
Tolmie, D F 2005. Persuading the Galatians. A Text-Centred Rhetorical Analysis of a Pauline Letter. In: Wissenschaftliche Untersuchungen zum Neuen Testament 2/190. Tübingen: Mohr-Siebeck.

Witherington, B 2004. Paul's Letter to the Romans. A Socio-Rhetorical Commentary. Grand Rapids, Michigan: Eerdmans Publishing Company.

\section{TREFWOORDE}

Identiteit

Verlossingsplan

Oorreding

Bybelvertaling

\section{KEY WORDS}

Identity

Plan of salvation

Persuasion

Bible translation

\section{KONTAKBESONDERHEDE}

Prof AH Snyman

Navorsingsgenoot: Departement Nuwe Testament,

Universiteit van die Vrystaat,

Posbus 339,

Bloemfontein.

9300 .

Tel: 051-4363405.

Sel: 0732153070 .

E-pos: asnyman44@gmail.com 